\title{
Education to Theatricality and Neutral Mask: Psycho-Pedagogical Approach
}

\author{
Gaetano Oliva \\ Faculty of Education, Italian Department, Catholic University, Milan, Italy \\ Email: gaetano.oliva@unicatt.it
}

Received 14 June 2016; accepted 24 July 2016; published 27 July 2016

Copyright (C) 2016 by author and Scientific Research Publishing Inc.

This work is licensed under the Creative Commons Attribution International License (CC BY).

http://creativecommons.org/licenses/by/4.0/

(c) (1) Open Access

\section{Abstract}

Education to Theatricality is pedagogical and artistic research; it is a science that includes different disciplines such as pedagogy, sociology, human sciences, psychology and the performing arts in general. The scientific basis of this discipline allows us to apply it in all possible contexts and with any individual, because it keeps the man in the center of its pedagogical process. One of the fundamental principles of Education to Theatricality is the development of the actor-person; the main aim is the development of creativity and imagination through a scientific training led by the actor on himself. This article introduces and analyses the Neutral Mask as an important element of theatrical pedagogy in relationship to its psyco-pedagogical aspect and as an educative instrument to train a person and to improve the development of creativity. The state of rest, calm, relaxing or suppleness silence is the starting point of every expression. The exercises with the neutral mask help students to investigate their inner world. When you wear the mask, you destroy the conception of time and of normally shared space, and the student has the opportunity to "dig" inside himself, facing his own identity. This essay presents the birth of the Neutral Mask in the Vieux Colombier School in Paris and explains its role in Jacques Copeau's pedagogy; then the article analyses the psycho-pedagogical elements that characterize its use in a laboratory of expressive arts; it gives a definition of laboratory and gives some exercises; in the end it specifies the role of masks in the dramatic play. Education to Theatricality as pedagogy uses the expressive arts into the theatre workshop to lead the subject onto a path of growth and training, activating the original potential skills of this person. An instrument such as the Neutral Mask, used during a theatrical workshop, allows to develop a greater self-awareness. By learning a silent language, a student can deepen the perception of his body and of his self-awareness through the use of Neutral Mask during a theatre workshop.

\section{Keywords}

Innovative Pedagogical Models, Art Education, Aesthetic Education, Early Childhood Education, Special Education, Theatre Education, Education to Theatricality, Neutral Mask 


\section{Introduction}

The Neutral Mask can be considered the result of an evolution of the use of masks in theatre history (Ebong, 1984). The mask (Bettini, 1992), in fact, has undergone great transformations according to the expressive needs of each era (Maertens, 1978); at the beginning it was used to personify a sort of bond between men and gods (Turner, 1967), then, over time, it was used for many different goals: for popular rites or to play the Commedia dell'Arte ("Comedy of Art") (Sartori-Lanata, 1983) that wanted to express the capability of man to transform himself playing animals, ancestors, gods, etc. (Ottenberg, 1982).

The Neutral Mask was born in France in the 20s, in Jacques Copeau's Vieux Colombier School (Copeau, 2000) (Leabhart, 1997: p. 17-34) in Paris; for the French pedagogue-director it was not a way of acting, but a training method for the students; this special mask, in fact, allowed to locate the body in a non-daily dimension but in an "universal" one, in a sort of neutral state of permanent discovery of life.

The Neutral Mask acts as an amplifier: when we hide our face even the slightest movement of the body has a great importance; so every student need to be able to perfectly control his body, being aware of each gesture. That will have to be very essential, because it has to summarize the multiplicity of reality. Working with the Neutral Mask every student starts an individual research that leads inward, searching the deepest feelings.

It was not a coincidence, in this regard, that psychoanalysis got interest in Neutral Mask and in the belief system that support the initiation rite, connecting it to Freud's Verleugnung (Freud, 1918). Masks were considered tools of metamorphosis, because they transformed people who put them on into those supernatural forces-gods, spirits, ancestors that man tried to control.

In modern society, Neutral Mask protects identity and assures anonymity, underlining a freedom which is temporarily granted. Moreover, it works on the pleasure that every man feels wearing a mask and pretending to be somebody else. In this transformation, the possibility of hiding maybe is more important than the possibility of expression. So we have a moralistic view of fiction, which is contained in so many metaphorical meanings that use the word "mask", such as a veil, as something which covers the authentic reality that is hidden, made deceptive. It is something to discover that is "behind" what conceals or alters it. The basis of this concept is the idea of identity and not of identification.

With the Neutral Mask, we have to hide our face, but not our identity; in fact, our identity occupies an intermediate space, and constitutes a kind of border. We have the visible body, which offers himself to the other as an object, and it appears as the substantial support for meaning creations, subject of expression, objective pole of recognition, created by the specific codes of a particular language. And at the same time we have a sort of interface with which every man can open himself to the world. It is a kind of porous screen through which we can establish a contact, an exchange, a transfer.

This double soul characterizes the face and allows a sort of double meaning, so we have the mask as fisiognomic expression and the mask as a secret.

Great expressive masks of historical tradition, are precisely expression of emotions because "they show" the states that define the subject as something visible, as something interpretable. A mask allows to see the veil that is applied to the face, prevents the objective vision of subjective identity by defining that soul whose eyes are the mirror.

As stated by Jacques Lecoq, the neutral gesture has no past and no passion (Lecoq, 2000). But normally the past and the passion are defined by the subjective idea, the philosophical idea of Ego, or the semiotical category of Me/You as the psychological and technical sense of speech production.

The Neutral Mask abolishes subjectivity. The neutralization of the face seems to assume a meaning that goes beyond technical operation of a specific modelling and seems, on the contrary, to intervene on the skills of expression, on the quality and on the origins of the donation in general. Actually, the face is exposed to a sort of neutralized nakedness, thanks to the Neutral Mask. It seems to show the value of a general function, a condition that transcends the singularity of our feelings. The face seems to be the general form on which is possible to create the polarities "subject-object" which constructs our way of giving value to the world and to what inhabits it.

Even in the dramatized ritual, the mind-body unity, conscious and unconscious, stillness and movement can find a shape. The theatre workshop is a planned path, projected, tested and then proposed in which we can use dance as a moment of discharge of physical tensions and we can use the mask to transcend the Ego and playing as a symbolic element.

It is important to enhance the use of the Neutral Mask in order to use it into educational psycho-pedagogical dynamics as a useful resource for improving the quality of people's life. 


\section{Neutral Mask: Appearance That Reveals}

\subsection{Vieux Colombier School: The Invention of Neutral Mask}

At the beginning, the masks used in the Vieux Colombier School were simple pieces of fabric that were wrapped around the face as a kind of glove, from this habit derived the expression to wear the mask, invented by a student but become common in the school. Then, even thanks to the experience of modelling led by the sculptor Albert Marque, they perfected the construction of the Neutral Mask (Copeau, 2000: p. 298-309).

Copeau (Kurtz, 1999) and Suzanne Bing-Copeau's collaborator and true life of the school saw in the Neutral Mask an extraordinary educational instrument: a working method and an educational instrument. "The Neutral Mask was very important for Copeau's pedagogy, because it owned the basics of educational and expressive process: the silence, the ability to listen to yourself, the freedom to experiment and express creativity" (Miglionico, 2009: p. 96); the complete education of the actor-person starting with the use of the languages of body.

Copeau realized that the mask help the actor's instrument-body to being put into play; first of all the Neutral Mask eliminated not only the word, but also the expression of the face, which are the two elements that every actor (and man) mainly used to communicate and to express ideas, emotions and feelings, at least in Western world in the eighteenth and nineteenth centuries. Through the Neutral Mask Copeau's student should not learn something, but, quite on the contrary, he has to free something of himself.

The work with the mask allows every student to experience himself in a very neutral and sincere situation, with a very intimate inner silence; the exercises were not aimed to train the actor; on the contrary, they wanted to create a contact between the man-actor and his own body and his emotions, so he could actually discover them, playing with them and experimenting them freely. The first goal was definitely educational. The student was not placed before the need to move towards an ideal model considered "right", he was encouraged to explore himself, bringing out and enhancing his skills: the training of every actor-person was the most important step, which is his human and expressive education through his theatrical training.

\subsection{Psycho-Pedagogical Aspects of the Neutral Mask}

Thanks to the Neutral Mask, every person better defines his body, improves his skills, and intensifies his capability to express values. The expressiveness of the person does not depend only on the facial expression but even on the gestures and on the actions of the body, because it is the only mean available to communicate. The development of self-expression is the starting point to play theatre, it is the first step to have a genuine dialogue with our Ego and with others, to be able to achieve a full acceptance of Ego and become aware of the language of the body.

The awareness of the Body and the relationship between Body and Identity are very important issues in the current pedagogical and psychological contemporary debate. Gamelli-pedagogue and professor of pedagogy of the body-writes: "The body is the central fact of our presence. We are not talking about the body that 'we have', the body that is described by science, but the body that we are, the living body, with whom we can create a relation with the others and with the environment".

[...]. The body-mind duality is linked to the body of abstract knowledge, not to the one connected to the experience of life. If we contact (again) the inner materiality of our inhabited and perceived body, it will help us to put us on the line, freeing the potentiality of languages that today are sacrificed by our culture, that talk so much about the body but considered it just a hedonistic object.

The body is the support of every kind of knowledge [...].

If we actually loose body, our culture may loose even soul, because it gets lost in a vision which is more and more linked to reason and to virtual learning.

Education to creativity is linked to a knowledge that is concrete, and it is a sort of a learning by doing, something useful to face efforts. In fact if the body can measure our limits, we have to be aware of it if we want to go beyond ours" (Gamelli, 2014: p. 69-71).

In these terms, the use of the Neutral Mask in the psycho-pedagogical project of Education to Theatricality (Oliva, 2015c) becomes a means by which each individual is enabled to experiment and find out what regulates movements, actions, gestures and through them rediscover his own Presence.

The Neutral Mask can be a tool to expand expressive skills, facilitating the access to the authenticity of Ego (Oliva, 2016: p. 24). So, a person that decides to cover his face accepts, a conception of time and space that is 
subjective and falls into a dimension that inwardly belongs to him, where he can purify and understand the body codes that emerges there. So we can have a sort of exaltation of the body dimension, and starting from it, everyone has a chance to dig into the Ego, to confronting with what appears as unknown and discovering a sort of uniqueness. From the moment in which the student wears a mask, he become free. For example, during the exercise of "await", he can feel free to feel hope, or disappointment, or joy. In fact the exercise does not consist in showing these emotions, but it allows the student to experiment what happens at an external level when he feels them. He can understand that he has to feel them to be able to show them, so that we need a state before every action.

With the mask he can understand which are the signs that have contributed to his state and which others are artificial or unnecessary; and moreover he can understand which interest or emotion of the viewer has a direct relationship with this sincerity (Copeau, 1988: p. 293). With these words, Copeau brings out the function and capacity of the Neutral Mask to be an instrument able to promote a sort of mediation between itself and the world, forcing the wearer to fully use his physicality to express any gesture. The author has underlined that the movement of the body reflects a precise inner condition, it enhances the communication qualities and it is able to express a sort of "transparency of actor's soul" (Oliva, 2010: p. 74).

The use of the neutral mask allows the wearer, to bring out through his body his uniqueness. Lecoq himself supports the same concept talking about "Neutral Mask that ends without a mask" (Lecoq, 2000: p. 50-53) showing that the Neutral Mask promotes a clearer perception of the body, and works on the expressive presence of every person.

Marco De Marinis explains that "our glance is the mask and the face of all the body. So our movements become much more powerful" (De Marinis, 2000: p. 170). So he is defining the true value of the Neutral Mask, which is considered as an important tool in theatrical pedagogy. Through this instrument you can give value to the qualities of each person respecting the personality, teaching to donate and to relate with others: "the movement through actions constitutes every person and creates the personality of the person himself" (Oliva, 2005: p. 282).

The psychologist Felice Perussia says: "The outward appearance (physical self-perception) has always been an important factor in the construction and presentation of Ego, and it has always been strongly involved in the development of relations. During the twentieth century, however, it becomes a material characteristic that every subject imagines being able to run on his own. It occurs that an increasing amount of constituent elements of physical appearance, that in other ages were considered as an independent variable, and now they become jurisdiction of the will. The subject perceives himself as responsible for his own shape (a body) [...]. And this sort of materialization of identity is what we need to make the new find, that is the discovery of being a body" (Perussia, 2003: p. 200-201).

This demonstrates that the body, in the complicated human phenomenon, is not just something you own but something that you live. Each individual, in order to fully achieve his spiritual Ego, can use his physicality because it is the real expression of his inner spirit and so can demonstrate that it is a very important part of his existence. Precisely the peculiarity of being a living body or a body who moves and makes actions becomes interesting at two levels: the expressive level and the psycho-pedagogical one.

The development of the awareness of the corporal Ego regards as much creativity as the development of personal identity; Perussia writes: "Our being in the world is basically a mise-en-scene. The individual exists, in large measure, because he is representing himself on the stage of the physical and social environment that surrounds him. Our actions (that is that we are actors) give, first of all, a shape to our intra-psychic representations through their concretely manifestation. They become a concrete thing (that is they become action) in the phenomenal reality as we perceive it and so we can structure them actively. Acting means to be spectators (inter-agents) of the actions of others, and of ours" (Perussia, 2000: p. 308).

The Neutral Mask gives every person a fundamental experience from an artistic and educational point of view: the chance to perceive himself a unity of body and mind in action. It offers everybody, in his own uniqueness, the ability to develop an awareness of the elements that constitute his skill to be in action: to perceive, observe, act and direct his action breaking it down and reassembling it intentionally (starting from a neutral body -the search of silence -the gesture and the movement also experimenting-getting in touch -with the inner emotional world through body language).

Being something important for someone else, to be in relationship with, have a relationship with someone, it is surely something that gives dignity back to every person, whoever he is, but, first of all, the essence of man 
consists to perceive his own individuality and identity.

He must perceive as the undisputed protagonist of his gestures and his actions, as a true advocate of the choices and changes, as a creator and a modifier of reality and, above all, as an artist of his own life. It can be said that the body exists as the ego does exist.

He must perceive himself as the undisputed protagonist of his gestures and his actions, as who actually make choices and changes, as a creator and a modifier of reality and, above all, as the artist of his own life. We can say that the body exists because Ego let it exist. Ego exists because it synthesizes and unifies the corporal activity. To build his identity, a man must be able to act, to create, to define, to challenge himself, and in turn the identity orients the concrete choices. He must therefore be able to be creative. Creativity and imagination are the intermediate space in which there are no models, where there are no deficits or impairments: the man as a man is creative.

The psychological and neuro-scientific contemporary studies have re-focused attention on the non-verbal language as an anthropological principle of communication and human relationships: "For millions of years, humans have communicated through not-verbal semiotic systems: verbal language appeared only later, grafting on a not-verbal communication and going to represent a different level of communication, more closely related to an activity of abstraction and symbolic production.

However, not-verbal communication remained as a fundamental dimension in the communication process; in particular, it is essential when we talk about the relational level because, as underlined by Anolli (Anolli, 2006), it intervenes in the manifestation of emotions and intimacy, in relations of power, in the phenomena of persuasion and seduction, in the creations of the image of Ego, as well as in the management of the conversation. Not-verbal communication manages first of all the relational component of the communication; communication, in fact, is not just about knowledge, information and thoughts to share with the interlocutor, but it is also about interpersonal relations: we have not to forget that through communication we create and maintain our relationships with others" (Feldman-Amoretti-Ciceri, 2013: p. 287-288).

\subsection{The Neutral Mask Workshop}

Before wearing the mask the students have to achieve two goals: knowledge and control of their breathing, acquiring of body awareness.

\subsubsection{Knowledge and Control of Their Breathing}

The subject must be conscious of his breathing (inhaling and exhaling) and of the changes in relation to different emotional and physical situations. Usually, in situations of anxiety or excessive physical exertion, breathing is short, frequent, rapid, because it is superficial. Instead, in calm physical and emotional situations, breathing is slower and deeper.

The educator to theatricality can help the students to reach this awareness, asking them to pay attention to their breathing when they experience different emotional and physical situations. Thanks to this attention, the teacher must lead students to understand that the deep breathing (using chest and abdomen) it the most effective for actions on stage. This allows the players to train and express themselves, vocally and bodily, longer and more strongly, because they have a greater amount of oxygen into their lungs (Oliva, 2015c: p. 176-196).

That explains the need to learn to control breathing. In fact, even if it is an automatic act related to lungs, every student can learn to control, to modify in amplitude, in frequency, in intensity and to stop it for a period of time. Being able to control breathing means to be able to manage every different emotional state, reaching with the deep breathing, a relaxed state which is important to be ready to play. The student who is wearing this kind of mask cannot afford a elaborated breathing because, having the face completely covered, he immediately feel himself suffocating. Learning to control breathing also has great educational value because it helps every person to quickly reach a state of tranquillity when he feels anxious or to afford great physical work. To achieve these goals there are several useful exercises (Oliva, 1999: p. 149-152).

\subsubsection{Acquisition of Body Awareness}

The body is a communicative language that expresses feelings, emotions, and messages. The subject must acquire knowledge and awareness of his own body to be able to use it in a conscious and intentional way. The subject wearing a mask cannot use facial expressions to convey his intentions, so he must use the rest of the 
body to communicate and to give value to the message that is contained in the mask. The student must sharpen the skill to perceive himself to better discover his own body; in fact he can communicate information about his posture, about the links between the body segments, about the degree of tension of muscles, and about the state of static and dynamic balance (Oliva, 2015c: p. 146-175).

The student must start from a relaxation state because, this state of lack of tension, helps him to listen to his own breathing, his heartbeat, but also to perceive his whole body and every single part. It is useful that the subject experiences how the change of the muscular tension can change the movement and how the same movement can assume different meanings when it is performed with different rhythm. Anyway, it is important that the subject can become aware of the general balance of different postures and that internalizes the feelings and the related muscle contractions necessary to maintain it. Preceding with this kind of exercises the student acquires gradually a greater body awareness, being able to move with much more confidence and mastery. On the other hand this awareness has a strong pedagogical value, because it is the basis of the construction and of the organization of personality, which is the result of the way of being of the individual, of his habits, his attitudes and his behaviour. So we can assert that personality is very influenced by bodily experiences (Oliva, 1999: p. 178-183).

\subsubsection{Wearing the Neutral Mask}

Every subject must respect a ritual when he wears a neutral mask and the educator should teach this ritual to the pupils. The ritual is useful to relax and to focus because it is an ensemble of precise gestures that should be repeated every time in the same way.

So the subject can memorize the sequence and then automatically reproduce it correctly, keeping the mind free and investing little energy, which can be ready to be used in the next step. Learning a ritual is even important from an educational point of view, in fact it allows the student to invest his energy in two different tasks at the same time; it gives the subject a sense of peace and tranquillity; it develops a sense of belonging to the group.

Léon Chancerel describes the ritual of wearing the mask as follows:

1. Getting the position. The actor must standing, keeping his feet well anchored to the floor. He should feel good, free to move.

2. Wearing the mask. The left hand hold the chin of the mask, and the other hand immediately puts the rubber around the head at the height of the temples that will keep the mask on student's face.

First step: the mask covered the head like a hat and the rubber will be at the height of the nape. Second step: the student lowers the mask on his face. Running these two steps without hesitation.

3. Relation. When the actor has wear the mask, he has to abandon himself, setting himself free, becoming "open", ready to receive the mask: a sort of soft skin who is waiting for a guest. The muscles should be relaxed, tranquil, the spirit should be empty. This change from real life to dramatic life is very important. This is the key of the masked game that will have so much dramatic power as this transmigration passage has been earnestly done (Chancerel, 1941: p. 134).

The subject who wears a mask for the first time must discover the appropriate way to make the action on the stage in a communicative way, through a training of continuous individual experimentation and reflections. When the first few time that an actor wears a mask, he feels its "physical presence": it can be annoying and pushing the subject to move in an unneutral way. Just when he becomes more familiar with it, he can discover its power and the possibility to feel free of constrictions.

With the personal construction of the mask, the actor has an advantage in using it, because he knows it since the beginning and he has created a relationship with it since the moment it was just raw material.

It is advisable to start the workshop using the neutral mask, because it does not contain a precise expressive condition and that set the student free to express. In a second step, the student can use expressive masks (Chancerel, 1941: p. 133-138), which force the subject to wear the face of another that is of the character (Ninnin, 1963). This step is possible only if the student has achieved a good self-awareness. The training with the mask during the laboratory is educational because it allows the student to regain and expand his skills of natural movement.

In the exercises with the mask the student could experience that state of "unmasked masked" (De Marinis, 2000: p. 170) in which he can discover the principles of construction and development of the movement, of the action and of the gesture. Copeau used the mask as a central element of his research process towards a new actor, a creative actor capable of using all its means of expression. The mask was considered a tool useful to expand the expressive possibilities, and to help the actor to access his authenticity. The Neutral Mask helps the 
student to understand and purify those signs that participate to a particular emotional state, to a certain attitude, it makes them more readable and therefore more clear for the communication.

\subsubsection{Exercises}

Copeau and his students, at the Vieux-Colombier School, experimented some exercises with the Neutral Mask. Suzanne Bing (Masques Dossier. Exercices de masque (1921-22) (Copeau, 1988: p. 292-297) and Marie Hélène Copeau trascribed them into the book "Masques et Improvisations" (Copeau, 2000: p. 298-309).

\subsubsection{The Preparatory State}

A precondition that defines the development of any action exists beyond the ritual of wearing the mask; everything comes from silence, from preparation, from the attention before any action; Marie Hélène Copeau recorded:

"Having the dramatic sense, means take possession of the other: leave ourselves to take possession of the other. You cannot donate yourself if you do not possess yourself ... To take possession of your Ego, you have to concentrate, to pay attention. You need a preliminary meditation before acting. With this meditation you can prepare the action. The preparation of the action develops inside the silence of meditation -then comes the waiting, the attack, and finally the action. The waiting is the midpoint, almost imperceptible between the meditation and the attack [...]. The movement is not the completion of the text -the action is the most important thing and the word is a sort of completion. The movements must be pure and simple, develop until their completion and make sense.

Precondition of any actions:

-To listen to yourself (silence, deconcentration)

-Meditation (preparation)

-Waiting

-Attack" (Copeau, 2000: p. 299).

The action should be developed through the readability of the direction of the movement and the continuity of state and of direction. About these two points Suzanne Bing transcribes in her diary: "We define "movement" the attitude of the gesture or even the look: it is every manifestation of a presence in a state of dramatic representation. We can define "direction" even if an abrupt change of movement if in it there is the readability of the expression: it is the obedience of the whole body to that organ that is mostly touched by the dramatic emotion.

To these principles we can add the idea of need: every superfluous or picturesque detail, even if it is right, damages the dramatic action [...]. The shape of the action is the result of the movement subjected to these principles. Thanks to the exercises with the mask the student can discover, experiment and better understand these principles.

The dramatic exercises with the mask reveals to the student the dramatic action in relation to himself, or rather reveals it to himself in relation to dramatic action. The most perfect state of a dramatic performance coincide to a complete identification, it seems that the exercises help the student to find the path of dramatic truth" (Copeau, 1988: p. 292-293).

\subsubsection{The Mask}

Marie Hélène Copeau notes: "Under the mask a student can suddenly feel a strength and a completely unknown mastery. When the face is hidden every student can recover the confidence, the security and he makes things that he could never dare without the mask. The mask requires a great strength and even a great skill in each movement, it demands well developed and complete movements, and they should have the same strong and regulated style of the mask.

The mask gives a great stability and a strong sense of measure -and also a kind of consciousness and self-mastery. Each movement should be done in relation to the mask. The mask has a lot of expression -it is not a contracted and acute expression, but a great, beautiful and simple expression, that we can already feel in spite of the inferiority of the masks that we used up to now. So we express through the mask, in a much more readable and surprisingly way, the feelings that we normally express with our figure" (Copeau, 1988: p. 300-301).

\subsubsection{To Start}

Marie Hélène Copeau transcribes "First exercises to learn to adjust the simplest gestures to the mask. When a 
student wear a mask, his movements must become slow, wide and simple, etc. First of all he must learn how to wear the mask: focus on himself before starting, to make himself free and open. Make this ritual without affectation (as often happens). This is an important moment before being completely captured by the mask and putting himself entirely at the service of the action that will be executed. It is actually necessary, physically vital, as well as the need of measuring by the eye, of balancing the body and legs to make sure that everything is OK, to prepare yourself to jump. We can compare it to the deep breath that you make in proportion to the distance you are going to swim underwater, focusing on the arrival point when you prepare yourself to dive. It is as easy as indispensable.

When you are well prepared: relaxed, silent and prepared, then you can wear the mask and it is like the curtain that rises: since this moment nothing can be indifferent. You are involved in the action. You have to start with simple slow gestures, maybe too slow, because you have to feel the pattern that they describe starting from immobility, outlining a certain trajectory, which should be totally visible to the viewer, before returning to immobility (Copeau, 1988: p. 296).

\subsubsection{Exercises for Arms and Hands}

The body and the masked head motionless (individual exercises):

1. Sitting on a chair. Wear the mask. Both hands resting on knees without rigidity; make three identical gestures with the left arm (simple gestures with one unique movement).

When the exercise is over and you return to the initial immobility, you have to raise the mask.

2. Same position. A gesture with the right arm, that starts and ends with the same motionless position on knees. Immediately after, you have to make the same gesture with the left arm ending with the same position on knees. Immediately after make the same gesture with both arms simultaneously.

3. Same position. A gesture with the right arm; when it is finished you have to make a different gesture with the left arm, then another with the right, and then another with the left. Finally a identical gesture with both arms at the same time.

4. Repeat all of these exercises in the same way, but instead of making each time only a simple gesture in a single motion, you have to make a gesture composed of two, three or four movements.

For example: raise the arm with a clenched fist, then open the hand; two movements.

The arm raises with the closed hand, the hand opens; the hand makes a sign while it closes, as it is telling something like "come", or you raise a finger, etc.

Three movements etc.

5. Make all these exercises standing, well-stable, without moving the rest of the body, or move your legs" (Copeau, 1988: p. 296).

\subsubsection{Exercises for Groups of People and Choral Exercises}

"When we talk about an exercise to do with two or more persons, we need a preliminary work: these persons have to run together, in harmony, a certain action. Therefore, they must tune themselves (as the instruments of an orchestra get tuned before starting a symphony). To make this possible, one person of the group (who will be nominated at the beginning by the workshops' leader) takes on the role of the tuning fork. He has to tune the others, which will have to be subordinated to him. He will be the game master, or coryphaeus.

The others must pay continuous attention to him, let him lead them. If the initiative, the beginning of a movement which must be performed together, by two or more persons, starts by more than one point, the harmony is not perfect. The attack of the person who runs the exercise, or better the moment that immediately precedes his attack (which corresponds to the moment when the orchestra leader raises his baton and holds it before starting to give the rhythm) must be felt by all the others with the clarity of a command. This command is indispensable to any choral action, even the simplest, but it may happen that it can be too strong. Gradually this command and this obedience will have to become a natural harmony and this habit to disciplines should produces a free and perfect ensamble" (Copeau, 1988: p. 296-297).

Marie Hélène Copeau annotated some choral exercises: "The group is sitting in a semicircle on the floor, with legs crossed and the head leaned on legs; relaxation. A sound is the signal to raise the head-he head pull on the torso until it is straight, then the head falls back. Exercise developed in three steps that in two steps. A choral exercise with the mask, well-coordinated and well defined, whatever it is, it is always beautiful" (Copeau, 2000: p. 305). 


\subsubsection{Exercises about the Directions and the Continuity of Action}

We write here two exercises of improvisation about the directions and the continuity of the action in relation to part of the body that "leads" (before the eye then the ear) (Copeau, 2000: p. 302-304).

The eye is the part of the body which is attracted.

The eye is the part of the body which is attracted. Its movement is directed towards a stove.

1) first step: "wear" the mask; absence of action or other preparatory action: standing, examine the room, hands behind the back, against the wall;

2) the eye stops on the object (the stove), catching sight of it;

3) the desire to get closer to the object raises; the movement begins led by the eye: the head is attracted, then the body, the feet are last part that move, the body is slightly tilted forward. The action lives without interruption. The curiosity increases, the desire to touch raises. Hands are moved from the back forward, taking much more importance as they were initially invisible;

4) touch the object, and perform analysis: completion of the action, relationship among the different steps of the action. The completion of the action, that is the examination of the stove in this exercise, should be proportionate to the rest of the action.

The ear is the part of the body which is attracted.

The ear is the part of the body which is attracted. Its movement is directed towards the place from where the sound comes. The intensity of the movement is linked to the intensity of the sound.

1) first step: "wear" the mask;

2) absence of action. The student is sitting on a chair beside a table, with his legs crossed, and reads a book;

3 ) he notices a noise, raises the head suddenly, turns towards the noise (movement led by the ear). He pays attention for a while, another noise from another direction captures his attention. He turns his head. While he is listening to it, the noise starts from another point. These noises become more and more frequent and produce an acceleration of the movement.

4) the fear pushes the student to abandon the book; he stands up; the noises start again more or less intensive, more or less frequent; the ear attracts the body, which tilts forward following the different directions.

The attitude is characterized by the fear and the attention.

\subsubsection{From the Awareness of the Body to the Improvisation of the Group or of the Individual}

The exploration work with the Neutral Mask has been developed after the experience of the Vieux Colombier by different theatrical pedagogues; we report some Lecoq's exercises (Lecoq, 1997) reworked by the Center of Theater Research "Theatre-Education" of Fagnano Olona in Italy (Oliva, 1998,: p. 122-189). The sequence is developed from de-mechanization work that is the discovery of the awareness of the body and the early works of composition through short individual and group improvisation experiences.

Awareness of the body or the de-mechanization

Stand. Wear the mask. Focus on a single part of the body: start a de-mechanization of right hand fingers, one at a time, slowly. Then make a de-mechanization of the whole hand; then the wrist, the elbow, and finally the shoulder. Then the neck, and, separated, the head. From the head the movement continues to the left side of the body: left shoulder, elbow, wrist, hand and fingers. Make a de-mechanization of the bust. Continue with the lower limbs: the buttocks, knee, ankle, toes, etc.

Perform all movements as slowly as possible and gestures are as wide as possible.

You can do this exercise even while sitting down.

The mirror

In pairs. Wear the mask, facing each other. One leads the other who "copies" like in a mirror all the movements in an identical way.

The movement of the two persons must be almost in a perfect harmony, from the outside you should not understand who is the mirror and who is the conductor; to create this harmony the participants should have a good relationship. The conductor must do simple and slow movements and gestures, the mirror must pay a lot of attention.

After a while the conductor and the mirror exchange their roles.

The mirror can be performed in three positions: standing, kneeling and lying on the ground.

The theme of awakening

Wear the mask. Everyone is sitting on the ground, with the legs crossed and the head lied onto the legs; relax. 
The awakening starts raising head and it gives direction. Then the movement involves arms, bust, and so on until the student stands up. The movements are slow and delicate, and it is a "dance": the awakening.

From the awakening to an exercise of ensemble

Everyone is sitting on the ground, with the legs crossed and the head lied onto the legs. Sweet awakening. The head moves and gives the direction; the body starts to move slowly. De-mechanization. Slowly every part of the body starts to move. The de-mechanization leads the body and the student stands up. The student starts to walk and follows a precise direction. The student stops and creates a shape with his body. The student starts to walk again and to meet other persons. They play a mirror exercise. Near of far mirrors. The student creates relationships with small groups of four or five people. One leads and others follow, and then they exchange their roles. Then they start to walk again. Repeat.

\section{Individual improvisations}

Wear the mask. Improvise two short tales. When a student improvises he has to look for simple gestures, to find the few gestures needed to tell the elements of the story that can be put on stage. Improvisation can be repeated several times, to remove and eliminate the movements and gestures that are redundant, unnecessary, repetitive, unclear. The work with the mask has as a precise goal; it looks for the essential and the precision of gestures and the stylization of forms.

The man in the desert

Once upon a time a man was deeply sleeping.

When he awoke he made a shocking discovery.

He was in a desert. The sun was high and he immediately felt very hot.

Looking around he could not believe his eyes: the sand beneath him, a blazing blue sky sun over his head, everywhere endless horizons.

He could not stay there because nobody would come to help him.

The thirst began to torment him. He decided to look for water. But where?

He saw far away a dark spot: he hoped was an oasis.

He started walking in that direction.

He fell over several times because of fatigue and discomfort. But he was tenacious and so every time he started to walk again.

After a while that seemed an eternity he reached the oasis, which fortunately was not a mirage.

He hurried up: there was a puddle of water among some palms.

He drank greedily refreshing himself.

Then, tired but refreshed, he fell again asleep.

The man in the woods

Once upon a time a man was deeply sleeping.

When he awoke he made a shocking discovery.

He was in a forest. The sun did not penetrate through the dense trees and immediately felt very cold.

Looking around he could not believe his eyes: tall trees obscured the sky, foliage and lush vegetation prevented to see further. Often he hears animal sounds that he had never heard before and suddenly he saw the leaves move eve if there was not wind at all.

He could not stay there because nobody would come to help him.

The vastness of the forest began to oppress him. He decided to look for a way out. But where?

He saw the remains of what once might have been a path.

He started walking in that direction.

Fatigue and obstacles made him fell over several times. But he was tenacious and starts to walk again.

After a while that seemed like an eternity the vegetation became less dense.

He hurried up: he saw a nice green lawn. The sky was again clear and blue; the sun warmed him up immediately.

He breathed in deeply.

Then, tired and refreshed he feels again deeply asleep.

\subsection{Reflections about the Laboratory}

The Neutral Mask was the most important instrument of Jacques Lecoq's educational process, exactly because of its qualities and its psycho-educational and expressive potential. He explains: "The neutral mask is a particu- 
lar object: it is a face, defined neutral, that suggest the physical sensation of calm. This object that you put on your face should allow you to achieve the state of neutrality which precedes the action, a state of full receptivity, without internal conflicts. This is a reference mask, a basic mask, a mask to support the others. We have a neutral mask under every mask, even if it is an expressive one or a mask of the Commedia dell'Arte. The neutral mask permits to the others to manifest themselves. When the student will have experienced this neutral starting state, his body will be available as a blank page on which he can write the drama [...]".

A neutral mask, as indeed all the masks, should not adhere completely to the face. It must keep a certain distance between the face and the object, and because of this precisely distance the actor can really act. Similarly the mask should be slightly larger than the face [...]. The neutral mask essentially develops the actor's presence in relation to the space that surrounds him. It helps the actor to develop a state of discovery, of openness, of willingness to receive. It allows the actor to watch, understand, feel, touch the elementary things, with the freshness of the first time [...]. The neutral mask is in a state of equilibrium, of economy of movements [...]. The neutral mask helps those who in life are in conflict with themselves, with their body, to find a point where breathing is more free. The neutral mask becomes a point of reference for everybody.

Under a neutral mask the actor's face disappears and we can perceive more clearly the body. Generally when we talk with somebody we watch his faces. When there is a neutral mask, the entire body of the actor is watched. The look is the mask and the face is the whole the body. All the movements are thus revealed in a powerful way. When the actor takes off his mask, if he has actually worn it, his face is relaxed [...]. The mask has extracted from him something that deprived him of all artifice: then, he has a beautiful open face. Once acquired this readiness, the mask can be removed, without worrying over gesticulation or didactic gesture. The neutral mask ends without a mask. [...] The mask sometimes causes unexpected reactions to the first contact: some people cannot stand it on their face, because they have the feeling of choking; others, more rarely, tear it away.

When students wear for the first time the neutral mask, I ask them which kind of feelings they tried and if they can express them even with a single word. Some of them say nothing, and that is fine. Others "discover their body", or find that "it is slower". All these impressions are released immediately after the first experience, do not require any comment. They are "right" (Lecoq, 2000: p. 50-53).

These words highlight all the elements that led Copeau to deepen that instrument discovered almost by accident. Lecoq says that the balance of the mask transmits to students who wear it the physical sensation of calm. It help them to be it in a state of receptivity and awareness first and foremost to themselves, favouring a state of equilibrium also with respect to internal conflicts (the Neutral Mask helps those who in life are in conflict with yourself, with your body, find a physical point of support, real and thus testable, where breathing is more free), then in relation to the space that surrounds the pupil. It facilitates the discovery, openness and availability is to either to experience. Under a Neutral Mask actor's face disappears and we can feel much more clearly the body. Every movement become cleaner, slower, more precise and more powerful. The mask works on the person's expressive presence.

Lecoq's words "show how the neutral mask is actually a powerful instrument to help the man to create a communication with his soul, with his inner beauty; the art of theatre, through this instrument, finds its highest fulfilment, helps the human being to deprive himself of every kind of artifice and teaches him to give himself to himself and to relate to others: when the actor removes the mask he has a beautiful, friendly and relaxed face" (Miglionico, 2009, p. 92). Lecoq emphasizes even the role of the pedagogue as a guide for the students: he must be a strong presence, safe, constant but he should never lead by example; during the work with the masks he must leave students free to exercise, accompanying them but remaining aside: "the function of the teacher is to indicate the drifts of the movement without ever indicate what needs to be done".

He has to leave hover doubt: "it is up to the students to find out what the teacher already knows. The teacher should always put himself on the line, find the freshness and innocence of the eye, in order to avoid imposing every kind of cliché" (Lecoq, 2000: p. 63).

An important element is the verbalization at the end of the work, in which each student must find the freedom of not-judgment to express what he felt: some of them react with a rejection, a feeling of suffocation, anxiety. Others "discover their bodies"; all the feelings that are released immediately after the first experience should be accepted without any comment, they are right. They are the experiences that the student has felt in contact with himself, a first step towards a higher consciousness.

The work with the mask in Copeau School is presented as indispensable since it develops the perception, the awareness and the use of the body and of the body movement. It may be considered an example that sums up the 
high educational value of Copeau's search, whose actor's school was, first of all, the manifestation of a theatrical pedagogy that aspired to be education of men who could also become actors. Reading students' impressions after the exercises we can understand that the work with the body is not just a body activity but it opens to a deep knowledge. The "player" feels free, he discovers his body but also his feelings, his emotions, his personality, and he becomes more aware and much more ready to communicate with others. The work with the mask is crucial not only because it is an instrument for the development of self-awareness, but because it open the way towards the dramatic truth (in a sincere relationship with themselves, with their own feelings, and with others) (Oliva, 2010: p. 70-77).

The Neutral Mask, precisely because of its complexity, is even today a basic instrument. The exercises should be gradual. They start with a purely individual work of experimentation. Then there are simple improvisations, where the actor-person, with the mask, develops a simple action with a beginning, a central part and a conclusion. Finally we have a teamwork. Starting with the work of the individual the teacher can propose the development of group improvisation during which the students can represent a range of feelings to form a dramatic chorus (Chancerel, 1941, p. 133-138).

The Neutral Mask can be used to "develop an adequate perception of the body, to work on the decomposition of the gesture and of the movement, but also as a first kind of exploration of the emotional area. Its use became essential because it helps the student to recognize himself and his feelings and to express them" (Miglionico, 2009: p. 106).

The mime improvisation becomes a training work to develop listening skills and the ability to capture the different aspects of the emotional sphere that is related to the inner world and to the way in which everyone can relate to each other (showing their emotions and representing them).

\section{The Dramatic Play}

Starting from his experience in the Vieux Colombier School under the guidance of Jacques Copeau, Leon Chancerel (Romain, 2005) began to define the concept of dramatic play (Oliva, 2010: p. 83-145) that is the dramatic experience with an expressive and educational function for the kids and for teens. Chancerel writes: "dramatic plays? We have chosen the word play. It implies on the one hand that this activity is a normal childhood activity. It implies, on the other hand, rules and conventions. We have chosen the word dramatic instead of theatrical because the last one evokes the idea of stages and public performance. We need a word that discards these notions, and evokes just the idea the child is expressing himself with actions just for his pleasure and for his own amusement. The dramatic plays will give the children a way to externalize through movement and voice, their deep feelings and their observation" (Chancerel, 1942: p. 5).

The idea, the working methodology and the dramatic play pedagogy are studied by Education to Theatricality in relation to the modern psycho-pedagogical studies (Oliva, 2010: p. 149-302).

"The dramatic play is a method with which the laboratory is taking shape for the age groups of younger children. In situations built for the dramatic play children play together, they recognize the presence of others; this game is an individual creation, but in a group work. The dramatic play arises from the preparation of children to learn through play. Starting from it develops spontaneous activity through drama and testing of languages, primarily the body, and is characterized by precise rules, such as to accept the participation of others, to uphold the choice, take a few moments and observe in the role of spectator. The educator in the dramatic play is a fundamental element, intervenes in the game, providing incentives, guidance and recognizes each student the opportunity to be placed in a new situation, with a different role. The dramatic play is an excuse to ensure that the child puts into play its expressiveness and become aware of his languages in a playful situation, learning to express themselves, to externalize their drives, their inhibitions, their desires. One way in which the game takes dramatic life is the dramatization of a story, where each child takes the role of a character chosen highlighting the features through the conscious use of body language. During the narration of the stories, the characters are interacting, policies and dialogue between them" (Oliva, 2015c: p. 353).

The dramatic play is an individual creation but at the same time is also a group activity, discovered through the educator who takes on a specific role. This game is characterized by precise rules, including the idea to accept the participation of others and the cooperation of the different elements that make up the group. As in spontaneous play, even in the dramatic play every child has a reason to act, but the individual action is limited to an action that serves the ensemble's project: only what is included and fits in the project can be done. 
So children are not as free as in the free play. Everyone must continue to act his role, either during a sequence or during the entire duration of the acting play. Moreover not all students in a class can play at the same time and they accept to not participate; they will be the spectators, but they know that next time it will be their turn. Not-participants can make suggestions, intervene and integrate the participants if someone does not want to continue if the group, with the agreement of the adult, creates a new role.

The educator to theatricality is not excluded; he intervenes when his presence becomes necessary by enforcing rules and orders, by asking the appropriate explanations related to certain actions to allow the game to continue, by being a referee in case of conflict and also allowing and regulating the introduction of new items in the course of the action. In dramatic play, the child is not as free as in spontaneous play, but he creates relations with his peers and he discovers this relationship while he is living them. However, he is aware that such activity is fictitious, that is similar to the regular play. The dramatic expression is like every kind of play, a pleasant time: the child is happy in fact to act, talk, invent and externalize his own state. Having received such a role that allows him to feel "big"; he is also pleased to have an audience made up of "not-participants" and of the adult, who is seen as a key element because he authorizes, promotes the play and especially recognizes that each child has the opportunity to be placed in a new situation, with a different role.

An integral part of dramatic play is the work on the awareness of body and mimic language. The pedagogical process starts from the neutral mask and from the mime to gradually develop child's expression, up to the construction and use of expressive masks. Chancarel, after some exercises with his students, writes: "It seems to me that the action wearing the mask is actually unmasked, because if on one hand it helps to overcome shyness and embarrassment of having a pair of feet and hands, that a person cannot use, on the other hand it will set free a certain part of ourselves (I admit the least bad) and opens a window by which we can escape. The mask helps us to honest, to get inside another human being and then to let us live and breathe forgetting the produced effect".

Another one: The play with the mask? Within that work, all that is the annoying "me" (stereotyped gestures, common words, limits) disappears to allow to the true and beautiful "me" to show itself. What can be grown without selfishness or pride is the most profound originality of the "me" that each individual always realizes, for such a small part of what it is, the beautiful perfect being. This play, to be good, must transform the student from a passive state to a full relation, to the total surrender, and is this not the same attitude of children? His abandonment, his confidence in life that is so simple and true? To be good actors with a mask you need to rejoin the intuitive childhood vitality (Chancerel, 1941, p. 133-138).

\subsection{The Neutral Mask and the Dramatic Play}

Wearing a mask is something link to the human instinct, because it is connected with the magical charm of expression and transformation. For these reasons, the mask is a useful instrument in the dramatic play for child's education, which starts from the rediscovery of its natural expressiveness and then he creates the character creation. In this regard Chancerel says: "Masks should be used when the characters represented by the children do not correspond at all to their age or their physiognomy, whatever if they are complement or initial element of the costume" $[\ldots]$.

The mask must be made in the same way as the costumes and realized in correspondence with the costume, with a direct relationship. Moreover, it must have a sort of general line that will be shown and highlighted especially by the nose and by few neutral colours [...]. No naturalism, no copies of real figures, but stylizations of ridiculous or serious characters. Carefully avoiding any polychrome excess" (Chancerel, 1942: p. 137).

Wearing the mask, the child overcomes fears and shyness, because it is hidden to others and his own eyes; he feels more relaxed and focused, sincere and willing to open himself to pay a greater attention to self-discovery, to experimentation and to express their personal background, their creativity. In other words, there is a process of liberation of mind, of body and soul. The acquisition of knowledge and self-awareness, the expression and the enhancement of creativity are useful to the child that can understand the basic elements of artistic expression, and that can takes possession of his personality.

Wearing the mask also means trying to overcome limits, leave individuality to take another face. This is a sort of answer to the human aspiration to open up to the imagination and momentarily change personality. Through the mask, the child approaches to the character and thanks to it he can learn a different way to think, to speak, to act; so, the student can learn to project "out by itself", that is, to overcome his egocentricity, succeeding to respect and understand the other's point of view: he acquires the basic elements necessary to establish a relationship. 
The use of the mask forces the subject to discover a more precise expressiveness and a greater understanding of his own feelings, so that the construction and the communication of his character can be intentional. Chancerel says: "If the character is mute, you can use an entire mask; if the actor has to speak, he must wear a half-mask that hides the upper part of the face. The latter one is more easily adaptable to the face or at least avoids to underline that annoying line indicating the separation between the mask and the neck. When you make it, you have to take in mind the actor's chin that will wear it because the form of the chin could totally change the appearance of the mask. The spectator can see the chin and the baby's mouth, but this characteristic gives more life to the mask giving it a sort of mobile element that does not prevent its immobility" (Chancerel, 1942: p. 138).

Through this kind of use, children are also educated to taste, because the costumes, the environment, the gesture, the voice should be adapted to the characteristics of the character.

\subsection{Building a Mask}

An important instrument in the dramatic play is the use of the mask, but also its construction, conceived in relation to the needs, the capabilities and the age of the subject.

In the laboratory of Education to Theatricality that students have to build (Oliva, 2010: p. 212-214), to colour, to decorate by their own the mask they should wear. In fact the conception and the realization are important activities from the artistic and educational point of view, but also because, with this kind of experimentation, the student can acquire a better knowledge and a greater familiarity with the mask itself, being able to better understand its secret.

Making masks is a fascinating and enjoyable activity for children but also for adults, because the mask is an object that has always attracted man: it allows you to transform reality, to hide identity, to get in touch with supernatural element forces, to overcome anxieties and fears.

Furthermore, craft and construction activity, responds to a motivation present in every man; the need to make, to create with his own hands something new. This is possible if, in addition to the use of one's body, a man uses the intellect and the feelings to create an original product.

Unlike written expression, all forms of manipulation, being closer to the perceptive experience, do not require the use of formal thought and so they are more suitable to any age. This experience is typical of the child: he learns to discover the world through sensory manipulation, as well as through exploration. In addition, the achievement of a practical result makes the experience intensely motivating even for the most "troubled kids".

Building the masks does not mean creating from nothing, but to transform something that already exists: manipulate materials such as paper and scotch tape to create something new; then, the realization of this process involves the use of cognitive and creative skills, which, through their use, can be developed. Chancerel writes: "To produce the masks, the easiest thing is to buy cheap masks. They are stiff, ugly and expressionless; so we need to modify them: first of all we have to change colour, painting them or with applications of paper, fabric, wool, etc. Then we need to give them a shape, for example by putting a second nose, adjusting the beard, eyebrows, etc. For the hair we can use different materials: feathers, furnishings cords, straw, wool, fabrics, etc." (Chancerel, 1942: p. 138).

So, the realization of the masks is the result of integration between the process of internalization, that is the acquisition of knowledge and skills required for the construction of the product and the process of externalization, that is the expression of creativity.

The knowledge and cognitive skills that are improved and used change during the different stages of construction of the mask; the expressive creativity, instead, is used and developed in every step. This means that the activity of realization of the masks is a great experience for the development and the expression of one's personal style. It is an opportunity to help the student to elaborate those elements that autonomously mix together, and they will assume little by little stability, giving a personal characterization of what he has produced.

Moreover, this experience allows the development of aesthetic sensibility, both as awareness to the style of a certain period or author, both as acquisition of aesthetic taste. So, each student will learn to understand what shape, what size, what colours will be used for the mask of a particular character. Chancerel says: "To make a mask, there is the method of modelling but it requires some particular skills, and of course inspiration and ingenuity. When you have to play the role of an animal you can make a one-piece costume or simply some masks. These masks can be realized with cardboard, hard paper, fabric or fur; it is important to stylized them and try to 
emboss them trough their own shape or with spots of colour. Wearing these masks, less than not having specifically designed them to allow the passage of the voice, cannot pass a word" (Chancerel, 1942: p. 138).

However, this is possible just if the educator will guide appropriately the subject in this experience rich of stimuli and materials, taking into account age but also the intellectual, emotional and creative development of the student.

\subsection{The Construction Mask Process}

The construction mask process includes several different steps that can be performed by children during the laboratory of Education to Theatricality in a dramatic play context (Oliva, 2010: p. 214).

\subsubsection{Step 1: Choice of Character}

A mask comes to life when it is worn, because the action of the subject gives value to the message contained in it (Oliva, 2010: p. 214-215). Therefore it makes sense to build masks that will be worn by becoming the face of a specific character. So, before designing and building a mask, you must choose the character; the whole process will depend on that choice it. The character with the mask can be an object (leaf, wind, river, etc.), an animal, a human being, a monster, a supernatural entity; it can be real or fantastic and be represented on stage with or without a mask. The decision to put a mask on a character must be taken in a conscious way and have a precise reason. According to the targets, the choice of the character can be proposed by the educator or by the students.

\subsubsection{Step 2: The Choice of Mask Features}

To determine the characteristics of the mask we have to start with the study of the character (Oliva, 2010: p. 215), that is, with the acquisition of knowledge related to its appearance, its nature, its history.

We can get this kind of information thanks to a direct observation (with the senses or the memories) of people, animals and objects that related to the character itself. Another way to get information is the indirect observation that is reading written or iconographic documents inherent this character. Sometimes, the obtained information is insufficient to define the characteristics of the mask; it becomes necessary to integrate them with others data from similar sources. Other times the information is numerous and divergent: so we have to make to a choice in relation with the methodology, with the targets and with the personal style. The mask is the face of the character, so we must know and understand the expressive language of any face. A face is defined by its contour, its shape and the position of the eyes and of the mouth; a profile is defined by the line of the jaw, of the nose and of the forehead. The face can therefore be inserted in fixed and mobile lines. Fixed lines are linked to the forehead, the nose and the chin, and they define the proportions of the face, representing a wide range of body types. The mobile lines are linked to eyes, eyebrows, mouth and wrinkles and they express the feelings.

By varying the relation between these lines you can obtain many different expressions.

To create a mask, you need to choose the fundamental physical and psychological characteristics of the character, deciding later which proportions and attitudes to depict. The observation is an important means to know and understand the language of the face: the actor learns to read in a more conscious and specific way every kind of emotion on others' face. Further, using the observational skill we can strengthen it and so we become more able to find clear and systematic information from reality. Observation is also a necessary precondition for the creative expression. The perceptual experience, in fact, allows the development of the mystical images, that is, of mental representations of the objects, which are the link between the use and production.

\subsubsection{Step 3: Choice of Material for the Construction of the Mask}

The choice of material (Oliva, 2010: p. 216) for the construction of the mask depends on several factors. If you want to build caricatural masks, schematic or symbolic masks or make animals, flowers or fantastic characters you should use paper, fabric, foam, polystyrene, that is it is better to use the techniques without mold. If you want to create expressive masks and keep precisely the anatomical variations it is better to use materials like paper maché, leather, gauze, and all the techniques with the mold, obtained with clay.

The choice of materials also depends on how long you are going to use the mask. For example if you want to use this scenic artifice for a long time, it is essential to use durable and transpiring materials, such as leather and paper maché. Moreover different techniques have different difficulties, so the choice of materials must also take into account the principle of gradualism, that is the age and familiarity that students have with the art of making 
masks. Leather masks are the most complex, they require technical and artistic skills; simple mask can be obtained, for example with paper and cardboard, and they are very suitable for children. In fact, Chancerel in dramatic play suggests to use paper: "The crepe paper will be taken into good consideration because of the numerous and fresh colours that are currently on the market -and not only the crepe paper (you can, to make it more durable, paste it on a piece of canvas), but every type of coloured paper, lucid or opaque, rigid or soft, silver and gold. There are green and red metallic paper, produced by specialized factories, that can have beautiful effects" (Chancerel, 1941: p. 59).

You can even use recycled materials which are cheap and easy to find and they are useful to improve imagination and creativity. You can use empty packaging, cardboard boxes, paper bags, old clothes, pieces of fabric, wool, plastic bottles and anything else that can stimulate the imagination. The kind of experience that the subject will have during the realization of the mask will depend on the different materials that he will use.

\subsubsection{Step 4: The Choice of the Shape of the Mask}

The choice of the shape (Oliva, 2010: p. 216) of the mask depends almost exclusively on its function. The masks that cover only the eyes and generally are realized with paper, cardboard or tissue, and they are mostly used during the carnival and not so often used in theatre.

The mask that covers the entire face is suitable for almost every occasion but, in particular, for the plays in which the emission of the voice is not constant. The masks that cover half face, leaving the mouth uncovered, allow a more free expression and mobility, resulting suitable for prolonged use.

Those masks that cover the whole head are advisable for the representation of flowers, plants, animals and fantastic creatures. They have a great figurative impact and they are perfect to be wear in large spaces indoors or outdoors. The masks that leave the face uncovered and that are wear like a hat and are animated with the movement of the body and of the head, make alive the natural rigidity of the mask.

\subsubsection{Step 5: Planning the Mask}

Before starting with the practical realization of the mask it is important to define it making a preliminary draw (Oliva, 2010: p. 217), in other words it is important to make sketch, to highlight the volumes, cavities and facial protrusions. To give it expressiveness is necessary to highlight and stylize graphically the features of the selected character with light and dark, studying and comparing the various possible solutions. First of all you have to draw the fixed lines of the face that is the nose, mouth, forehead and chin. Then you have to draw the mobile lines of the face, that is, the folds of the eyes, eyebrows and mouth, so you can visualize the expression that you want to get with it. We must consider the mask as a whole, drawing the subject by the front or by profile. Then you have to give volume to the drawing with dark and light, darkening the hollows and facial folds with pencils or watercolours. It is important to take into account the measurements of the face and of the head of those who will wear it. Key measures are: the width and circumference of the face; the length of the face from hair to the neck; the position of the eyes in relation to the vertical midline of the face and the horizontal line of the eyes. If, however, the mask covers the entire head, you also need to know the measures relating to it. You will need to plan these data, using a compass, a caliber and a tailor meter copying them on the mask. This important step is an enjoyable activity, because drawing is a spontaneous activity, present since early age. The realization of drawings depends on both the observational skills of the subject and skills relating to the age and the personal style. The drawing is an important moment for the success of the mask, and it is a useful tool for the development of expressiveness, for the recognition and reproduction of shapes, for the achievement of hand-eye coordination and acquisition of aesthetic sense. This step allows the switch from the use to the production: the task becomes more challenging. The subject must be able to make an immediate elaboration of the information, a translation into images, an interaction with the drawing through corrections and an evaluation of the obtained result, in addition to the work of analysis and synthesis of its fruition.

\subsubsection{Step 6: Construction of the Mask}

The moment of the realization of the mask (Oliva, 2010: p. 218) is very satisfying for the man, because it responds to his natural propensity of doing. This is a plastic activity, a kind of modelling through which the subject enters into a relationship with some different objects: the material and the tools. It acquires the experience of tactile perception that is of manipulation, through which the subject becomes aware of the physical characteristics of these objects. In other words he discovers that things are different for slipperiness, roughness, elasticity, 
hardness, malleability. He experiments different materials and develops a three-dimensional perception, but also the fine motor skills, that involve the use of hands and fingers, and he acquires a greater knowledge of reality and of its formal structures such as symmetries, inequalities and regularities.

The discovery of the materials is not only a perceptual tactile experience, but also something related to sight, to hearing and to the sense of smell. The material has, in fact, different colors, smells and sounds. So, the player can discover that the materials also have a symbolic value: a color, a smell, a shape, a texture can cause different emotions and references. Become familiar with the material can helps him to discover its secrets and to use consciously its properties and its potential. This perceptual experience also enhances images, which are necessary for the development of creativity. This one is the result of a process of representation, of construction, of consideration, of synthesis and of evaluation.

\subsubsection{Step 7: Coloration and Decoration of the Mask}

The player can put on makeup on masks but also paint and decorate them (Oliva, 2010: p. 219) without limits to imagination. Varying colours you can get different results from the same mask, because of the high symbolic and expressive potential of them. Watercolours can create delicate shades so they are suitable for creating shades on gauze and papier-mâché masks. The gradient can also be obtained by the use of oil colours which, when get dried, acquire a semi-bright tone. Acrylics are smooth and opaque so they are useful as background colours or to create strong dark and light variations. With colours it is possible to proceed in different ways and with various techniques that can be discovered by the subject in the testing phase. In this way he will understand and use the expressive and symbolic potentialities contained in colour. The masks can also be decorated with any material, selected and used following creativity (Doda, 1983): natural elements such as leaves, twigs, or with various inserts of cloth, plastic...

\section{Conclusion}

The Ego is the object of the research of many scientists in the fields of physics, neuro-sciences, microbiology. Everyone is looking for an equation, of a definition, of a principle that is able to unify all the forces acting in the universe. The aim is to know yourself; this statement may appear to be banal, but it is not, because people think they know each other, but actually they just know the masks which are added to the Ego.

Such confusion produces a bewilderment equal to the loss of vision that characterizes a hypnotic state, a sort of sleepwalking or state of a drugged subject; we have an idea of ourselves but it is quite far from the truth, extraneous to the facts because as long as the person does not know himself, he cannot recognize the masks. Becoming aware of the innermost Ego, the subject not only recognizes the masks, but it gets harder to wear them. He puts them on just when they are essential for operating in this human dimension, as those who wear a suit being well aware that it is something that you can put on and take off.

Making this comparison, the personality is a mask that the subject wears to create a relation with the society and the mask is a kind of compromise between the demands of the individual and those of the surrounding society. The society is a masquerade ball and has a great respect for the mask, for who wear it, and especially for those who know the utility; unfortunately, the vast majority of people wears a mask but does not know. These people totally identify themselves with a mask that can be the body, the social role, the task that can lose their way.

The question is how to get closer to your awareness and which tools to use to do that. The Neutral Mask and its use during a theatre workshop, give a greater self-awareness, by learning a silent language that allows to get a deeper perception of the body and to increase the self-awareness.

There are three fundamental aspects which have been developed in this work: the movement, which simply implies a movement of the whole body or of a part of it; the physical action, which is an movement that produces an effect; and finally the gesture, identifiable with a specific movement, usually of the head or of the hands, which presupposes an individual's intention in relation to the pursuit of a specific purpose (Oliva, 2014b).

It is through this knowledge and practical experimentation that you can reach a state of full awareness of yourself, in other words to know at any moment your feelings and preferences and being able to use this knowledge to address every decision making process. Having a realistic evaluation of the skills and a well-founded self-confidence means: 
-Emotional Awareness: being able to recognizing emotions and their effects;

-Self-assessment: knowledge of your strong points and limitations;

-Self-confidence: trust your value and capabilities.

In the work with the Neutral Mask we can discover an important link with the identity, because during the practice and exercises, the person did not lose it, but puts it aside to make an exploration of the different potential he possesses. The body is used to express a free and unconditional communication, without any set codes (Oliva, 2015b).

For all these reasons, the Neutral Mask is a valuable tool during an Education to Theatricality workshop, which is a laboratory that aims to develop the psyco-physical and social well-being of a person but also his artistic personality. Education to Theatricality has the goal to educate people through expressive arts and to educate them to the expressive arts by developing the creativity and personal expression of each one (Oliva, 2015a: p. 89-91).

The Education to Theatricality is an interdisciplinary science that includes performing, expressive and literary arts but even other human sciences, like pedagogy, psychology, sociology, philosophy, anthropology (Oliva, 2014a: p. 1764).

His aesthetic and artistic philosophy is based on the concept of art as a vehicle by Grotowski but he processes it: Education to Theatricality, in fact, considers all the expressive arts and all artistic languages as possible vehicles of the training of the person. The study (learning), the practice (doing) and the knowledge (learning by doing) of expressive and performative arts become the instruments to develop self-awareness and awareness of relational and communicational skills and so to improve the growing of the whole person (learning by existing).

The art is then understood in its formative sense: getting aware of expressive languages and being able to manage them help every subject to elaborate a process of analysis and self-knowledge that promotes a double growth, existential and artistic.

The Education to Theatricality defines the idea of actor-person (Oliva, 2015b: p. 89-90), in fact it considers the aesthetic and artistic dimension of the human being as an intrinsic quality. The word actor is linked to its etymological sense of "the person who performs the action"; such action can be developed through any expressive language (verbal language, non-verbal language, the language of space and or of using materials, the write language, the language of music, graphic and pictorial languages).

In this light Education to Theatricality does not propose a specific model oriented to the domain of a particular style of communication, but the contamination between different forms of creativity. Looking for a communication that can be adequate to the needs of the contemporary context, it create a link with the tradition, analyzing pedagogies and using the methodological elements studied in the history of the theatre, with a particular reference to the directors-pedagogues and theatre pedagogues of the twentieth century.

The process of personal research (Oliva, 2015a) can therefore be represented by the formula (Oliva, 1999: p. 89):

"PRE-EXPRESSIVITY + METHODOLOGY = DEVELOPMENT OF INDIVIDUAL CREATIVITY"

The proposed methodology is based on (Oliva, 2015a: p. 91) behaviours that support the search, such as:

-Avoiding standard attitudes;

-Help every individual to discover his skills;

-Refrain from any value judgment;

-Pay attention to any point of view;

-Promote all languages;

-Counteract the tendency to passivity;

-Avoid any imitative process.

The aim is to help every person to develop an individual artistic and relational model, a model that may be unique and inimitable as every person is.

\section{Note}

The in-text citations are translated by the author.

\section{References}

Anolli, L. (2006). Fondamenti di psicologia della comunicazione (EN: Fundamentals of Psychology of Communication). Bologna: Il Mulino. 
Bettini, M. (1992). La maschera, il doppio, il ritratto. Strategie dell'identità (EN: The Mask, the Double, the Portrait, Identity Strategies). Roma-Bari: Laterza.

Chancerel, L. (1941). Le théatre et la jeunesse (EN: Theater and Youth). Paris: Édition Bourrelier \& C.

Chancerel, L. (1942). Les jeux dramatiques (EN: Dramatic Play). Paris: Éditions du Cerf.

Copeau, J. (1988). Il luogo del teatro. Antologia degli scritti (The Place's Theatre. Anthology). A cura di Editor Aliverti, M. I., Firenze: La Casa Usher.

Copeau, J. (2000). Reg. VI. L'École du Vieux Colombier (EN: Logbook VI: The Vieux-Colombier School). Paris: Gallimard.

De Marinis, M. (2000). In cerca dell'attore. Un bilancio del Novecento teatrale (EN: Looking Actor. An Analysis of Twentieth Century Theatre). Roma: Bulzoni Editore.

Doda. A. (1983) Maschere, tecniche, idee, materiali per costruire (EN: Mask Making: Techniques, Ideas, Materials). Milano: Ottaviano.

Ebong, I. A. (1984). Mask and Masking: A Survey of Their Universal Application to Theatre Practice (Vol. 79, pp. 1-12). Freiburg, Switzerland: Anthropos Institut.

Feldman, R., Amoretti, G., \& Ciceri, M.R. Eds. (2013) Essentials of Understaning Psychology Psicologia Generale. Milano: McGraw-Hill.

Freud, S. (1918). From the History of an Infantile Neurosis. London: Vintage.

Gamelli, I. (2014). Corpo (EN: Body). Saggio contenuto In C. Benzoni (Ed.), In una parola (pp. 69-71). (Text within: C. Benzoni (Ed.). In a Word (pp. 69-71)). Varese: Benzoni Editore.

Kurtz, M. (1999). Jacques Copeau: Biography of a Theatre. Carbondale: Southern Illinois University Press.

Leabhart, T. (1997). Modern and Post-Modern Mime. New York: St. Martin's Press.

Lecoq, J. (1997). Le Corps poétique (EN: The Poetic Body). Actes Sud-Papiers, un enseignement de la création théâtrale, en collaboration avec Jean-Gabriel Carasso et Jean-Claude Lallias, collection "Cahiers Théâtre/Éducation", Anrat (Association Nationale de Recherche et d'Action Théâtrale).

Lecoq, J. (2000). Il corpo poetico. Milano: Ubulibri. (Edizione italiana)

Maertens, J. T. (1978). Le masque et le miroir: essay d'anthropologie des revêtements faciaux (EN: The Mask and the Mirror: Anthropological Testing of Facial Elements). Paris: Aubier Montaigne.

Miglionico, M. (2009). Il progetto educativo del teatro di Jacques Copeau e l'Educazione alla Teatralità (EN: The Education Project of the Theater of Jacques Copeau and Education to Theatricality). Arona: Editore XY.IT.

Ninnin, G. (1963). Maschere e costumi (EN: Masks and Costumes). Brescia: La Scuola Editrice.

Oliva, G. (1998) Educare al teatro (EN: Theatre \& Educazion). Brescia: Editrice La Scuola.

Oliva, G. (1999). Il laboratorio teatrale (EN:The Theater Workshop). Milano: LED.

Oliva, G. (2005). L'Educazione alla Teatralità e la formazione. Dai fondamenti del movimento creativo alla form-a-zione (EN: Education to Theatricality and Training: From the Creative Movement to Form in Action). Milano: LED.

Oliva, G. (2010). L'Educazione alla Teatralità e il gioco drammatico (EN: Education to Theatricality and Dramatic Play). Arona: Editore XY.IT.

Oliva, G. (2014a). Education to Theatricality inside Secondary School, Art and Body. CE: Creative Education, 5, 17581775. http://dx.doi.org/10.4236/ce.2014.519197

Oliva, G. (2014b). Education to Theatricality: Creative Movement as a Training Model. Global Journal of Human-Social Science: G Linguistics \& Education, 14, 1-20.

Oliva, G. (2015a). Education to Theatricality: Expressive Arts as Pedagogy of Creativity. International Journal of Social Science Studies, 3, 87-95. http://dx.doi.org/10.11114/ijsss.v3i3.745

Oliva, G. (2015b). Education to Theatricality: The Theatrical Workshop as a Training Model the Expressive and Performing Arts in Education. Journal of Education, 5, 86-114. http://dx.doi.org/10.5430/wje.v5n2p86

Oliva, G. (2015c). Education to Theatricality. Saarbrucken: Lap Lambert Academic Publishing.

Oliva, G. (2016). La maschera neutra (EN: Neutral Mask). Scienze e Ricerche (No. 23, pp. 17-24). Roma: Agra Editrice.

Ottenberg, S. (1982). Illusion, Communication and Psychology in West African Masquerades Ethos ( Vol. 10, pp. 149-185). Wiley Library-American Anthropological Association.

Perussia, F. (2003). Theatrum Psychotechnicum: L'espressione poetica della persona (EN: The Poetic Expression of the Person). Torino: Bollati Boringhieri.

Perussia, F. (2000). Storia del soggetto. La formazione mimetica della persona (EN:The Ego's History. The Mimetic Formation of the Person). Torino: Bollati Boringhieri. 
Romain, M. (2005). Léon Chancerel. Un réformateur du théâtre (1886-1965) (EN: Léon Chancerel. A Reformer of the Theater). Lausanne: Editions l'Age d'homme.

Sartori, D., \& Lanata, B. (1983). Arte della maschera nella commedia dell'arte. (EN: The Art of the Mask in "Comedy of Art”). Firenze: Centro maschere e strutture gestuali: La casa Usher.

Turner, V. (1967). The Forest of Symbols. Ithaca: Cornell University Press.

Submit or recommend next manuscript to SCIRP and we will provide best service for you:

Accepting pre-submission inquiries through Email, Facebook, Linkedin, Twitter, etc A wide selection of journals (inclusive of 9 subjects, more than 200 journals)

Providing a 24-hour high-quality service

User-friendly online submission system

Fair and swift peer-review system

Efficient typesetting and proofreading procedure

Display of the result of downloads and visits, as well as the number of cited articles

Maximum dissemination of your research work

Submit your manuscript at: http://papersubmission.scirp.org/ 